\title{
An Exploration of Affect Factors and Their Role in User Technology Acceptance: Mediation and Causality
}

\author{
Heshan Sun \\ School of Information Resources and Library Science, University of Arizona, Tucson, AZ 85719. \\ E-mail: hsun@email.arizona.edu \\ Ping Zhang \\ School of Information Studies, Syracuse University, Syracuse, NY 13244. E-mail: pzhang@syr.edu
}

\begin{abstract}
Affect factors have gained researchers' attention in a number of fields. The Information Systems (IS) literature, however, shows some gaps and inconsistencies regarding the role of affect factors in human-computer interaction. Building upon prior research, this study aims at a better understanding of affect factors by clarifying their relationships with each other and with other primary user acceptance factors. Two affect variables that are different in nature were examined: computer playfulness (CP) and perceived enjoyment (PE). We theoretically clarified and methodologically verified their mediating effects and causal relationships with other primary factors influencing user technology acceptance, namely perceived ease of use (PEOU), perceived usefulness (PU), and behavioral intention (BI). Quantitative data were analyzed using R.M. Baron and D. Kenny's (1986) method for mediating effects and P.R. Cohen, A. Carlsson, L. Ballesteros, and R.S. Amant's (1993) path analysis method for causal relationships. These analyses largely supported our hypotheses. Results from this research indicate that a $P E \rightarrow P E O U$ causal direction is favored, and PEOU partially mediates PE's impacts on PU whereas PE fully mediates CP's impact on PEOU. With the increased interest in various affect factors in user technology acceptance and use, our study sheds light on the role of affect factors from both theoretical and methodological perspectives. Practical implications are discussed as well.
\end{abstract}

Along with unprecedented advances in information systems (IS), user technology acceptance research remains a focal topic. After decades of research, this area is considered by some researchers to be one of the most mature areas in contemporary IS literature (e.g., Venkatesh, Morris, Davis, \& Davis, 2003); however, there are still understudied areas, unanswered questions, and inconclusive results. Researchers have mostly focused on the extrinsic motivational (or utilitarian) side of IS. The intrinsic motivational side, especially the

Received January 3, 2006; revised December 1, 2007; accepted December 1, 2007

(C) 2008 ASIS\&T • Published online 28 March 2008 in Wiley InterScience (www.interscience.wiley.com). DOI: 10.1002/asi.20819 affective aspect, is to some extent understudied (Agarwal \& Karahanna, 2000).

Affect is conceived as an umbrella concept for a set of more specific mental processes including emotions, moods, and attitudes (Bagozzi, Gopinath, \& Nyer, 1999; Liljander \& Mattsson, 2002). Affect has been proven to have significant impacts on social judgment, consumer preference, and employee job satisfaction (e.g., Forgas, 1995; Weiss, 2002; Weiss, Nicholas, \& Daus, 1999; Zajonc, 1980; Zajonc \& Markus, 1982). Recently, IS researchers have started to examine the affective side of IT from various perspectives such as trait versus state (e.g., Csikszentmihalyi, 2000; Venkatesh, 1999; Webster \& Martocchio, 1992), antecedent versus consequence of cognition (e.g., Compeau, Higgins, \& Huff, 1999; Van der Heijden, 2004; Venkatesh, 2000; Yi \& Hwang, 2003), and positive versus negative (e.g., anxiety) (e.g., Compeau et al., 1999; Hackbarth, Grover, \& Yi, 2003; Thatcher \& Perrewe, 2002).

However, in general, the specific roles of affect factors in user technology acceptance are less clear and are inconclusive from both theoretical and empirical perspectives. Nowadays, considering the ubiquity of information technologies (ITs) for nonutilitarian purposes in work and nonwork environments, it is important to understand the affective aspects of user technology acceptance. Even for systems mainly with utilitarian purposes, due to the availability of a large number of competing products for the same purposes, the affective aspect of information systems deserves a better understanding for its implications to user technology acceptance.

Therefore, the objective of this research is a better understanding of the role of affect factors in user acceptance of technology. Specifically, we consider two affect variables, computer playfulness (CP) and perceived enjoyment (PE). $\mathrm{CP}$ is frequently used to reflect the trait aspect of users' interactions with computers and is stable over time. CP can be viewed as an indicator of the general trait of playfulness in the domain of information systems. PE, on the other hand, is often referred to as a perception, as suggested by its 
name, of the enjoyableness of a particular technology (Davis, Bagozzi, \& Warshaw, 1992). PE is a state variable and can change dramatically over time and across systems. Two gaps in the literature are of special interest to this research: (a) the unstudied connection between $\mathrm{CP}$ and PE, and (b) the unclear causal relationships between $\mathrm{PE}$ and perceived ease of use (PEOU). Theoretically, CP as an IT-specific trait should influence PE because the literature in other disciplines mentioned earlier suggests a trait-state link. It seems that state affect is able to mediate trait affect's impact on behavior. Yet, to date, the direct relationships between $\mathrm{CP}$ and PE have not been examined, although they are frequently studied together. Without considering their relationship, the results may be misleading. For example, Venkatesh (2000) found that CP and PE were two significant antecedents of PEOU; however, the relationship between $\mathrm{CP}$ and $\mathrm{PE}$ was not tested. The relationships $\mathrm{CP}$ and PE have with PEOU may vary if we consider the $\mathrm{CP} \rightarrow \mathrm{PE}$ link. In addition, the causal relationship between PEOU and PE is not clear. PE has been conceptualized as an antecedent of PEOU (PE $\rightarrow$ PEOU) (e.g., Venkatesh, 2000; Venkatesh, Speier, \& Morris, 2002; Yi \& Hwang, 2003) or as a consequence of PEOU (PEOU $\rightarrow$ PE) (e.g., Davis et al., 1992; Igbaria, Iivari, \& Maragahh, 1995; Igbaria, Parasuraman, \& Baroudi, 1996; Teo, Lim, \& Lai, 1999; Van der Heijden, 2004). The conflicting arguments could be problematic since researchers have to propose both causal connectedness and causal direction among constructs when studying mediating effects.

The remainder of this article is organized as follows. First, we describe the conceptual development including the research framework and hypotheses. We then present the methodology used in this study, followed by empirical results. We conclude by discussing limitations and implications.

\section{Conceptual Development}

\section{Constructs of Interest in this Research}

Two affect factors of particular interest to this research are $\mathrm{CP}$ and PE. Both have received some attention in the IS literature. Yet, we found that they have been studied in isolation from each other: Their relationship has not been studied. To examine their roles in user technology acceptance, we also consider other major factors influencing user technology acceptance: behavioral intention (BI), perceived usefulness (PU), and PEOU.

Computer Playfulness. A trait is an enduring predisposition to respond to stimuli across situations, and reflects a static aspect of information processing that impacts a broad range of variables (Weiss, 2002; Weiss et al., 1999). General traits refer to comparatively stable characteristics of individuals that are relatively invariant to situational stimuli (Webster \& Martocchio, 1992). General traits of playfulness have been empirically confirmed to be a predictor of affect state or average level of mood, a prolonged affective state (Weiss et al., 1999).
Unlike general traits, situation-specific traits are becoming more widely utilized in the literature because they relate more strongly than do general traits to organizational outcomes. Situation-specific traits are traits that are enduring and predispose individuals to respond to stimuli in a consistent manner within a narrowly defined context or group of target objects (Thatcher \& Perrewe, 2002). Situation-specific traits are more likely to operate in certain sorts of situations and not others (Day \& Silverman, 1989; Thatcher \& Perrewe, 2002; Webster \& Martocchio, 1992).

In the IS literature, a situation-specific trait is offered by Webster and Martocchio (1992), who defined CP as an individual characteristic representing a type of intellectual or cognitive playfulness and describing an individual's tendency to interact spontaneously, inventively, and imaginatively with microcomputers (p. 202). CP represents a stable aspect of users' interaction with computers. Moreover, CP has been confirmed to be temporally stable and system-independent, two characteristics that are considered the two generally accepted criteria of personality traits (Yager, Kappelman, Maples, \& Prybutok, 1997). First, Yager and colleagues (1997) confirmed CP's temporal stability by conducting a longitudinal study within a 5-week period. That is, $\mathrm{CP}$ can be stable over a relatively long period of time such as 5 weeks. On the other hand, state variables hold for just seconds or minutes. Second, the system independency means that $\mathrm{CP}$ indicates an individual's general likelihood of using various technologies. A user with high CP is generally more likely to indulge in using a new IT than would be a user with low CP.

Perceived Enjoyment. $\quad \mathrm{PE}$ is defined as "the extent to which the activity of using computers is perceived to be enjoyable in its own right, apart from any performance consequences that may be anticipated" (Davis et al., 1992, p. 1113). PE was referred to as an intrinsic motivation variable. Intrinsic motivation is defined as the doing of an activity for its inherent satisfactions rather than for some separable consequence (Ryan \& Deci, 2000). In contrast, extrinsic motivation, such as PU (discussed later), is a construct that pertains to whenever an activity is done to attain some external outcome.

PE differs from CP in two ways. First, PE does not have temporal stability, but is subject to change over time. A user could perceive a system to be enjoyable at one time but not at another. Second, PE does not have situational consistency and is system-dependent. That is, it basically measures how enjoyable an individual perceives interaction with a specific system.

The reasons that we select PE are twofold. First, PE seems to be a core component of many existing affective concepts. A review of contemporary research on affect in IS reveals that $\mathrm{PE}$ is a major component of many existing affective concepts such as flow (Csikszentmihalyi, 2000; Hsu \& Lu, 2004; Novak, Hoffman, \& Duhachek, 2002; Webster \& Martocchio, 1995; Webster, Trevino, \& Ryan, 1993), perceived playfulness (Liu \& Arnett, 2000; Moon \& Kim, 2001), and cognitive absorption (Agarwal \& Karahanna, 2000; Webster \& Martocchio, 1992; Yager et al., 1997). 
Second, PE has gained a lot of attention from researchers studying individual reactions toward IT (Atkinson \& Kydd, 1997; Igbaria et al., 1995; Teo et al., 1999; Van der Heijden, 2004; Venkatesh, 2000; Venkatesh et al., 2002; Yi \& Hwang, 2003). By considering this construct and using Davis et al.'s (1992) definition, we keep our research consistent with and comparable to previous research, and therefore this research could have wider influence.

Perceived Usefulness, Perceived Ease of Use, and Behavioral Intention. Three related variables-PU, PEOU, and $\mathrm{BI}-$ merit brief mention. Defined as "the degree to which a person believes that using a particular technology will enhance his performance" (Davis, 1989, p. 320), PU has been confirmed to be a strong, if not the strongest, predictor of behavioral intention (e.g., Davis, Bagozzi, \& Warshaw, 1989; Hu, Chau, Sheng, \& Tam, 1999; Mathieson, 1991; Taylor \& Todd, 1995a).

PEOU is defined as "the degree to which a person believes that using a particular system would be free of effort" (Davis, 1989 , p. 320) and has been used as an indicator of the perceived cognitive effort needed to learn and utilize IT (Gefen, Karahanna, \& Straub, 2003). The reason that PEOU is of interest to this research is that it is closely related to both affect variables mentioned earlier.

$\mathrm{BI}$ is used in this research as the surrogate for user technology acceptance. BI has been confirmed to be a valid and robust indicator of user technology acceptance and is influenced by both extrinsic (e.g., PU) and intrinsic motivations (e.g., PE and PEOU) (Sun \& Zhang, 2006a).

\section{Research Models and Hypotheses}

Research models. In light of the fact that existing findings regarding mediating effects are usually drawn from single models, we refer to Baron and Kenny's (1986) method of examining mediating effects as the guideline for model construction. According to Baron and Kenny, a variable serves as a mediator to the degree that it accounts for the relation between the independent and dependent variables. In situations where a causal linkage has been determined, an attempt should be made to show that " $\mathrm{X}$ causes $\mathrm{Y}$ through $\mathrm{Z}$ and that once $Z$ has been controlled, the relationship between $\mathrm{X}$ and $\mathrm{Y}$ vanishes" (Baron \& Kenny, 1986, p. 1177). In this case, $X$ and $Y$ are independent and dependent variables, while $\mathrm{Z}$ is the mediator. Baron and Kenny laid out three conditions that have to be met: (1) variations in levels of the independent variable $X$ significantly account for variations in the presumed mediator Z (Path a); (2) variations in the mediator Z significantly account for variations in the dependent variable Y (Path b); and (3) when Path a and b are controlled, the previously significant relation between the independent variable $\mathrm{X}$ and dependent variable $\mathrm{Y}$ is weakened or no longer significant (Baron \& Kenny, 1986, p. 1176). Therefore, examining mediating effects involves testing a set of regression models rather than a single model. Specifically, to test the mediation, one should examine three regression equations: (a) regressing the mediator on the independent variable, (b) regressing the dependent variable on the independent variable, and (c) regressing the dependent variable on both the independent variable and on the mediator (Baron \& Kenny, 1986).

Full mediation holds when the independent variable has no effect (i.e., the coefficient is zero) when the mediator is introduced. Full mediation implies a single, dominant mediator. When the coefficient is not zero (partial mediation), on the other hand, this indicates the operation of multiple mediating factors.

One underlying assumption of Baron and Kenny's (1986) method involves the presumed causal relationships among $\mathrm{X}, \mathrm{Y}$, and the mediator Z. However, as mentioned earlier, the causal relationships between PE and PEOU are not conclusive. Therefore, considering the two possible causal relationships between PE and PEOU: PE $\rightarrow$ PEOU and PEOU $\rightarrow$ PE, we construct the four models depicted in Table 1. Models 1

TABLE 1. Proposed models.

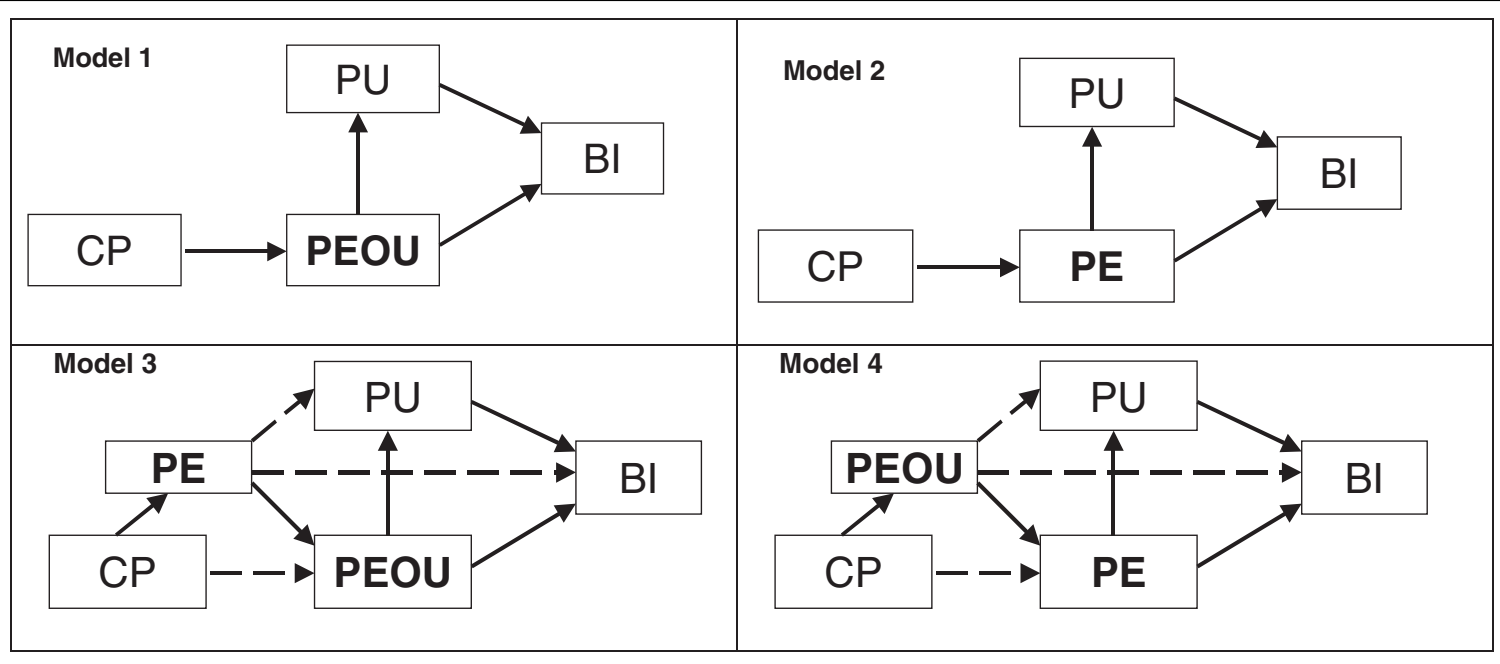

Dashed lines represent the relationships that are supposed to be weakened after the mediator is introduced in each model. 
and 2 are basis models whereas Models 3 and 4 are mediating models regarding the different causal directions $\mathrm{PE} \rightarrow \mathrm{PEOU}$ and PEOU $\rightarrow$ PE, respectively. The differences between Models 1 and 2 and between Models 3 and 4 are highlighted in boldface type.

Next, we present the corresponding hypotheses. Then we discuss the idea of examining a set of models (We call the set a combination.) for investigating the mediating effects following Baron and Kenny’s (1986) rules.

Hypotheses. Many links in the proposed models are well studied in the literature. Model 1 and Model 3 are based on the technology acceptance model (TAM; Davis, 1989; Davis et al., 1989) whereas Model 2 and Model 4 are based on the motivational model (Davis et al., 1992). These four models share some linkages/hypotheses because they are based on the same theoretical reasoning. To avoid repeated presentations, a shared link/hypothesis is presented only once, and we point out in which model(s) it would appear (as indicated in Table 1). The hypotheses will be presented in the rough order of the most common relationships to the least common or unique relationships.

The relationships among PU, PEOU, and BI are proposed in the original TAM and have been confirmed by the following studies. We thus do not focus on them. Without further discussion, we propose the following hypothesis, which appears in all four models:

H1: PU has a significant positive effect on BI.

H2: PEOU has a significant positive effect on BI.

H3: PEOU has a significant positive effect on PU.

It has been proposed that PE is able to influence users' BIs significantly. The rationale is that individuals who experience pleasure or enjoyment from using an information system are more likely to form an intention to use it than are others (e.g., Davis et al., 1992). This relationship has received a good amount of empirical support (Agarwal \& Karahanna, 2000; Igbaria et al., 1995; Igbaria et al., 1996; Teo et al., 1999; Van der Heijden, 2004).

The relationship between $\mathrm{PE}$ and PU has been relatively understudied (Yi \& Hwang, 2003). An intrinsic motivation variable such as PE is supposed to increase the deliberation and thoroughness of cognitive processing and lead to enhanced perceptions of extrinsic motivations such as PU (Bagozzi et al., 1999; Batra \& Ray, 1986; Venkatesh et al., 2002). Venkatesh and colleagues (2002) empirically confirmed the relationship between PE and PU. Similarly, Yi and Hwang (2003) proposed and empirically confirmed this relationship. People with a favorable perception of the enjoyment of a system are more likely to perceive it useful. Combined, we hypothesize the following two hypotheses that appear in Models 2 and 4:

H4: PE has a significant positive effect on BI.

H5: PE has a significant positive effect on PU.

$\mathrm{CP}$ predicts users' PEOU. The rationale is that people who are more playful with ITs in general are expected to indulge in using a system just for the sake of using it rather than for specific positive outcomes associated with use (Venkatesh, 2000). Users with higher computer playfulness view their interaction with IS more positively than do those less playful with computers. The playful users are more likely to underestimate the difficulties of using a technology since they simply enjoy the process and do not perceive it as requiring effort, compared to those who are less playful (Venkatesh, 2000). To identify the antecedents of PEOU, Venkatesh (2000) viewed $\mathrm{CP}$ as one of the "anchor" variables and tested its impact on PEOU. His results showed that $\mathrm{CP}$ in general has significant effects on PEOU. Similarly, in studying the mediating effects of affect factors on the relationship between prior experience and PEOU, Hackbarth and colleagues (2003) empirically confirmed that $\mathrm{CP}$ has a significant impact on PEOU. The following hypothesis is offered and appears in Models 1 and 4:

H6: CP has a significant positive effect on PEOU.

$\mathrm{CP}$ has a significant effect on PE. Agarwal and Karahanna (2000) argued that CP has a significant effect on cognitive absorption. Enjoyment, meanwhile, is one of the components of cognitive absorption with the highest loading. Similarly, Webster and Martocchio (1995) empirically confirmed that cognitive playfulness has a significant impact on flow, the state of playfulness. Given that cognitive playfulness is similar to $\mathrm{CP}$, in terms of their conceptualization and measurement whereas flow has a significant component of enjoyment, it is reasonable to propose a causal relationship between $\mathrm{CP}$ and PE. Moreover, prior research in marketing, consumer research, and organizational behavior has demonstrated a significant link between personal traits and state variables. Thus, we propose the following hypotheses in Models 2 and 3:

H7: CP has a significant positive effect on PE.

The previous discussions complete the hypotheses in Models 1 and 2. For the rest of the article, we concentrate on those unique relations in Models 3 and 4. These relationships reflect our main contribution in this article.

Model 3 is a mediating model with a $\mathrm{PE} \rightarrow \mathrm{PEOU}$ causal direction. Here, we focus on causal relationships that are either new or subject to change due to the introduction of mediating effects. That is, PEOU mediates PE's impact on $\mathrm{BI}$ and PU whereas PE mediates CP's impact on PE.

First, PE has a significant influence on PEOU. Positive affective perception makes users perceive themselves as possessing ample time to complete a task, which in turn reduces the perception of workload associated with using the technologies (Agarwal \& Karahanna, 2000). Enjoyment can make individuals "underestimate" the difficulty associated with using the technologies since they enjoy the process itself and do not perceive it to be arduous (Venkatesh, 2000). This relationship also has received empirical support (e.g., Yi \& Hwang, 2003). Therefore, we argue that:

H8: PE has a significant positive effect on PEOU. 
On the other hand, prior findings have suggested that the impact of PE on BI is fully mediated by PEOU. For instance, Venkatesh et al. (2002) failed to find a significant relationship between intrinsic motivation, which is identical to PE in terms of measurement, and behavioral intention. Instead, intrinsic motivation's impact is fully mediated by PEOU. Similarly, Venkatesh et al. (2003) argued that affect variables, which they called "attitudinal constructs," are significant only when specific cognitions such as effort expectancy, a concept similar to PEOU, are not included in the model. Therefore, the relationship between $\mathrm{PE}$ and behavioral intention is spurious and results from the omission of PEOU. Thus, we argue that

H9: PE has a weakened/nonsignificant direct effect on BI when PEOU mediates their relationship.

Given that the relationship between PE and PU is relatively understudied (Yi \& Hwang, 2003), we do not have much empirical support for the mediating effect of PEOU on this relationship. Earlier discussions about the mediating effect of PEOU on the relationship between PE and BI can be generalized to the relationship between PE and PU. Therefore, we argue that

H10: $P E$ has a weakened/nonsignificant effect on PU when PEOU mediates their relationship.

$\mathrm{CP}$ has a weakened effect on PEOU when PE is introduced as the mediator. Agarwal and Karahanna (2000) demonstrated that cognitive absorption mediates the effect of $\mathrm{CP}$ on PEOU. Similarly, Webster and Martocchio (1995) proposed and confirmed that flow, the state of play, mediates the impact of individual differences, including $\mathrm{CP}$, on training outcome variables such as satisfaction, learning effects, and posttraining reactions. Enjoyment is one of the major dimensions of flow (Csikszentmihalyi, 1988, 1990; Novak et al., 2002). Consistent with their findings, we propose that

H11: $\mathrm{CP}$ has a weakened/nonsignificant effect on PEOU when PE mediates their relationship.

Model 4 depicts a causal model where a PEOU $\rightarrow \mathrm{PE}$ causal direction is proposed. That is, PE mediates PEOU's impact on BI and PU whereas PEOU mediates CP's impact on PE. PEOU has a significant impact on PE. The rationale is that systems that are easier to use are likely to be perceived as enjoyable (Igbaria, et al., 1995). Igbaria et al. (1995) also cited Bandura's $(1977,1986)$ self-efficacy theory to inform the relationship between PEOU and PE. Self-efficacy has a significant impact on affect. Therefore, PEOU (similar to self-efficacy) has a significant impact on PE (affect). This relationship is empirically supported (Davis et al., 1992; Igbaria et al., 1995; Igbaria et al., 1996; Teo et al., 1999; Van der Heijden, 2004). Therefore, we hypothesize that

H12: PEOU has a significant positive effect on PE.
PE has been proposed to mediate the relationship between PEOU and BI (Davis et al., 1992). Previous research has provided moderate support for this mediating effect. In 2004, van Der Heijden found a significant relationship between PEOU and BI, which is partially mediated by PE. Igbaria et al. (1996) and Teo et al. (1999) found similar effects. We argue that PE only partially mediates the impact of PEOU on BI and PU. Therefore,

H13: PEOU has a weakened, but significant, positive effect on $\mathrm{BI}$ when PE mediates their relationship.

H14: PEOU has a significant, but weakened, effect on PU when PE mediates their relationship.

For the mediating effect of PEOU on the relationship between $\mathrm{CP}$ and $\mathrm{PE}$, we do not have much empirical evidence since, as we mentioned in the beginning of the article, little prior IS research has studied the direct relationship between $\mathrm{CP}$ and PE. We have proposed significant relationships between CP and PEOU and between PEOU and PE. According to Baron and Kenny's (1986) rule, to make an argument about PEOU's mediating effects, we expect that the direct relationship between $\mathrm{CP}$ and $\mathrm{PE}$ becomes weaker when PEOU is introduced as the mediator.

H15: $\mathrm{CP}$ has a weakened/nonsignificant effect on $\mathrm{PE}$ in Model 4 when PEOU mediates their relationship.

Combinations for examining mediating effects. According to Baron and Kenny's rules (1986), we combine the aforementioned models to test the mediating effects of PE and PEOU. Two combinations regarding the different causal relationships between PE and PEOU are discussed next.

Combination I: Mediating effects based on PE $\rightarrow$ PEOU. Combination I includes three models: Models 1, 2, and 3. Combination I examines three mediating effects that can be identified when a $\mathrm{PE} \rightarrow \mathrm{PEOU}$ direction is proposed (Table 2): (D1) PEOU mediates PE's impact on BI, (D2) PEOU mediates PE's impact on PU, and (D3) PE mediates CP's impact on PEOU. We compose conditions that have to be satisfied for each mediating effect in Table 2.

Combination II: Mediating effects based on PEOU $\rightarrow$ PE. Combination II includes Models 1, 2, and 4. It is used to examine three mediating effects that can be identified when a $\mathrm{PEOU} \rightarrow \mathrm{PE}$ direction is proposed: (D4) PE mediates PEOU's impact on BI, (D5) PE mediates PEOU's impact on PU, and (D6) PEOU mediates CP's impact on PE. Similarly, we compose the conditions that must be satisfied for each mediating effect, following Baron and Kenny's (1986) rule, in Table 3.

\section{Methodology}

Sample

A survey method was used to collect empirical evidence to test our proposed models. General Internet users were 
TABLE 2. Mediating effects in Combination I.

\begin{tabular}{|c|c|c|c|}
\hline Baron \& Kenny’s (1986) rule & D1. PEOU: $\mathrm{PE} \rightarrow \mathrm{BI}$ & D2. PEOU: $\mathrm{PE} \rightarrow \mathrm{PU}$ & D3. PE: $\mathrm{CP} \rightarrow \mathrm{PEOU}$ \\
\hline 1. IV $\rightarrow$ Mediator & 1. $\mathrm{PE} \rightarrow \mathrm{PEOU}$ is significant (Model 3); & 1. $\mathrm{PE} \rightarrow \mathrm{PEOU}$ is significant (Model 3); & 1. $\mathrm{CP} \rightarrow \mathrm{PE}$ is significant (Model 2); \\
\hline 2. IV $\rightarrow \mathrm{DV}$ & 2. $\mathrm{PE} \rightarrow \mathrm{BI}$ is significant (Model 2); & 2. $\mathrm{PE} \rightarrow \mathrm{PU}$ is significant (Model 2); & 2. $\mathrm{CP} \rightarrow \mathrm{PEOU}$ is significant (Model 1 ); \\
\hline $\begin{array}{l}\text { 3. IV } \rightarrow \mathrm{DV} \text { is weakened } \\
\text { when mediator is present. }\end{array}$ & $\begin{array}{l}\text { 3. } \mathrm{PE} \rightarrow \mathrm{BI} \text { link is weakened } \\
\text { when PEOU is added (Model 3). }\end{array}$ & $\begin{array}{l}\text { 3. } \mathrm{PE} \rightarrow \mathrm{PU} \text { link is weakened } \\
\text { when PEOU is added (Model 3). }\end{array}$ & $\begin{array}{l}\text { 3. } \mathrm{CP} \rightarrow \mathrm{PEOU} \text { link is weakened when } \\
\mathrm{PE} \text { is added (Model } 3 \text { ). }\end{array}$ \\
\hline
\end{tabular}

IV: Independent variable; DV: Dependent variable.

TABLE 3. Mediating effects in Combination II.

\begin{tabular}{|c|c|c|c|}
\hline Baron \& Kenny's (1986) rule & D4: PE: PEOU $\rightarrow$ BI & D5: PE: PEOU $\rightarrow$ PU & D6: PEOU: $\mathrm{CP} \rightarrow \mathrm{PE}$ \\
\hline 1. IV $\rightarrow$ Mediator & 1. $\mathrm{PEOU} \rightarrow \mathrm{PE}$ is significant (Model 4); & 1. $\mathrm{PEOU} \rightarrow \mathrm{PE}$ is significant (Model 4 ); & 1. $\mathrm{CP} \rightarrow \mathrm{PEOU}$ is significant (Model 1 ); \\
\hline 2. IV $\rightarrow \mathrm{DV}$ & 2. PEOU $\rightarrow B I$ is significant (Model 1); & 2. $\mathrm{PEOU} \rightarrow \mathrm{PU}$ is significant (Model 1); & 2. $\mathrm{CP} \rightarrow \mathrm{PE}$ is significant (Model 2); \\
\hline $\begin{array}{l}\text { 3. IV } \rightarrow \mathrm{DV} \text { is weakened } \\
\text { when mediator is present. }\end{array}$ & $\begin{array}{l}\text { 3. } \mathrm{PEOU} \rightarrow \mathrm{BI} \text { link is weakened } \\
\text { when PE is added (Model 4). }\end{array}$ & $\begin{array}{l}\text { 3. } \mathrm{PEOU} \rightarrow \mathrm{PU} \text { link is weakened when } \\
\mathrm{PE} \text { is added (Model } 4 \text { ). }\end{array}$ & $\begin{array}{l}\text { 3. } \mathrm{CP} \rightarrow \mathrm{PE} \text { link is weakened when } \\
\mathrm{PEOU} \text { is added (Model 4). }\end{array}$ \\
\hline
\end{tabular}

IV: Independent variable; DV: Dependent variable.

recruited. A total of 750 recruiting e-mail messages were sent. Gift cards were provided as incentives for participation. Among the 240 returns, 161 had complete responses for all measures. This set comprised the final sample used for data analysis. Among the respondents, $43 \%$ were male. The age distribution was 19-24 (15.6\%), 25-34 (42.5\%), 35-44 (20\%), and older than 45 (21.9\%). Sixty-eight percent (68\%) of them had more than 5 years of experience with search engines.

\section{Target Technology}

Web-based search engines were used as the target technology, for four reasons. First, although using search engines to find information is one of the major online activities, search engines have rarely been studied in prior research in user technology acceptance (for a review, see Legris, Ingham, \& Collerette, 2003). Second, search engines have both utilitarian and hedonic values. Thus, the use of search engines can make our results more generalizable. Third, prior studies traditionally have focused on the objective performance of search engines, such as recall, prevision, and response time (Chu \& Rosenthal, 1996). Subjective affective reactions toward using search engines, while of great value, have rarely been studied. For instance, examining search results, which also is a part of using search engines, can be fun and can influence users' acceptance of search engines. Note that although we allowed participants to use whatever search engines they liked, over $80 \%$ of them chose Google.com.

\section{Tasks}

We designed two simple tasks to collect participants' reactions to search engines. The first task asked participants to search answers to the following question: "What happened on this same day in history (historical events on this day in history)?" This was meant to be a fun process. The second task asked participants to recall a work-related problem, then use search engines to find answers. To ensure that participants examined the results, we asked each participant to list answers for both questions. After performing these two tasks, participants filled out the questionnaire. The purpose of these two questions was to position participants in the information search context and thus ensure that their answers were based on the recent experience (e.g., the two tasks).

\section{Operationalization of Constructs}

All constructs were measured using scales that were previously developed and validated: The seven-item Computer Playfulness Scale was used to measure Web-related computer playfulness (Agarwal \& Karahanna, 2000; Webster \& Martocchio, 1992; Yager et al., 1997), three items were used to measure PE (Davis et al., 1992; Venkatesh, 2000), four items were used to measure PEOU (Agarwal \& Karahanna, 2000; Davis, 1989; Davis et al., 1989, 1992; Gefen et al., 2003; Venkatesh \& Davis, 1996; Venkatesh et al., 2003), and two items were used to measure behavioral intention (Davis et al., 1989; Davis \& Venkatesh, 1996; Venkatesh, 2000). The instruments used in this research are listed in the Appendix.

\section{Data Analysis}

The partial least square equation (Version PLS-Graph 03.00), a structural equation modeling (SEM) technique, was used to analyze the data. PLS is a second-generation multivariate technique that facilitates testing of the psychometric properties of the scales used to measure a construct, as well as the estimation of the parameters of a structural model.

The measurement model in PLS was assessed in terms of item loadings and reliability coefficients (composite reliability) as well as convergent and discriminant validities. Individual item loadings greater than 0.7 are considered adequate (Fornell \& Larcker, 1981). A composite reliability of 
.70 or greater is considered acceptable (Fornell \& Larcker, 1981). The average variance extracted measures the variance captured by the indicators relative to measurement error, and it should be greater than .50 to justify using a construct (Barclay, Higgins, \& Thompson, 1995). The discriminant validity of the measures refers to the degree to which items differentiate among constructs or measure distinct concepts, and is assessed by examining the correlations between the measures of potentially overlapping constructs. The average variance shared between each construct and its measures should be greater than that shared between the construct and other constructs (Compeau et al., 1999).

The structural model in PLS was assessed by examining the path coefficients (standardized betas). $T$ statistics were calculated to assess the significance of these path coefficients. In addition, $R^{2}$ was used as an indicator of the overall predictive strength of the model.

Given the different causal directions between PE and PEOU, we also refer to Cohen et al.'s (1993) path analysis method. As will be seen in detail later, covariance-based methods, albeit robust in examining causal connectedness, are limited in detecting causal direction. Cohen et al.'s path analysis method, on the other hand, emphasizes the causal direction and therefore can be used as a supplementary tool for covariance-based statistical methods.

\section{Results}

\section{Measurement Models}

Tables 4 and 5 demonstrate the results for the measurement models. The results show that the measures of the constructs were robust in terms of item loadings, their internal consistency, reliability as indexed by composite reliabilities, and discriminant validity. Except for CPS1, all other item loadings were above the suggested 0.70 . The internal reliabilities, assessed by composite reliability, were all greater than 0.70 . Therefore, no items were dropped. This allowed comparisons with the measures used in prior studies. Tables 4 and 5 also demonstrate satisfactory convergent and discriminant validity of the measures. Average variance extracted for all constructs exceeded 0.50 . As for the discriminant validity, the results show that all constructs were more strongly correlated with their own measures than with any of the other constructs. Therefore, discriminant validity was observed.

\section{Structural Models}

Path coefficients and $R^{2}$ for the four models are shown in Table 6. Most of the hypotheses were confirmed. Two hypotheses ( $\mathrm{H} 4$ and $\mathrm{H} 13$ ) regarding the relationships between $\mathrm{PE}$ and BI and between PEOU and BI are not supported.

\section{Mediating Effects}

Based on the results of the structural models, Table 7 summarizes the results regarding the mediating effects and
TABLE 4. Item loadings in Model 3 and 4.

\begin{tabular}{llllll}
\hline & CPS & PE & PEOU & PU & BI \\
\hline CPS1 & $\mathbf{0 . 6 5}$ & 0.33 & 0.28 & 0.29 & 0.20 \\
CPS2 & $\mathbf{0 . 8 4}$ & 0.29 & 0.23 & 0.09 & 0.03 \\
CPS3 & $\mathbf{0 . 8 0}$ & 0.33 & 0.38 & 0.21 & 0.16 \\
CPS4 & $\mathbf{0 . 8 0}$ & 0.26 & 0.25 & 0.13 & 0.02 \\
CPS5 & $\mathbf{0 . 7 3}$ & 0.29 & 0.34 & 0.14 & 0.09 \\
CPS6 & $\mathbf{0 . 7 8}$ & 0.24 & 0.22 & 0.12 & 0.11 \\
CPS7 & $\mathbf{0 . 7 7}$ & 0.26 & 0.27 & 0.14 & 0.06 \\
PE1 & 0.27 & $\mathbf{0 . 9 7}$ & 0.67 & 0.57 & 0.43 \\
PE2 & 0.27 & $\mathbf{0 . 9 7}$ & 0.71 & 0.56 & 0.39 \\
PE3 & 0.28 & $\mathbf{0 . 9 6}$ & 0.63 & 0.59 & 0.43 \\
PEOU1 & 0.26 & 0.58 & $\mathbf{0 . 9 2}$ & 0.53 & 0.52 \\
PEOU2 & 0.27 & 0.68 & $\mathbf{0 . 9 2}$ & 0.48 & 0.47 \\
PEOU3 & 0.26 & 0.64 & $\mathbf{0 . 9 2}$ & 0.53 & 0.48 \\
PEOU4 & 0.28 & 0.67 & $\mathbf{0 . 9 4}$ & 0.54 & 0.53 \\
PU1 & 0.13 & 0.55 & 0.52 & $\mathbf{0 . 9 5}$ & 0.54 \\
PU2 & 0.11 & 0.56 & 0.54 & $\mathbf{0 . 9 0}$ & 0.55 \\
PU3 & 0.11 & 0.56 & 0.54 & $\mathbf{0 . 9 3}$ & 0.63 \\
PU4 & 0.13 & 0.53 & 0.51 & $\mathbf{0 . 9 4}$ & 0.58 \\
BI1 & 0.03 & 0.42 & 0.47 & 0.66 & $\mathbf{0 . 9 4}$ \\
BI2 & 0.12 & 0.37 & 0.55 & 0.48 & $\mathbf{0 . 9 2}$ \\
\hline
\end{tabular}

TABLE 5. Reliability, convergent, and discriminant validity coefficients (Models 3 and 4).

\begin{tabular}{lccccccc}
\hline & CR & AVE & 1 & 2 & 3 & 4 & 5 \\
\hline 1. CP & 0.909 & 0.589 & $\mathbf{0 . 7 6 7}$ & & & & \\
2. PE & 0.977 & 0.935 & 0.378 & $\mathbf{0 . 9 6 7}$ & & & \\
3. PEOU & 0.959 & 0.853 & 0.380 & 0.694 & $\mathbf{0 . 9 2 4}$ & & \\
4. PU & 0.962 & 0.864 & 0.217 & 0.594 & 0.565 & $\mathbf{0 . 9 3 0}$ & \\
5. BI & 0.929 & 0.867 & 0.131 & 0.427 & 0.542 & 0.619 & $\mathbf{0 . 9 3 1}$ \\
\hline
\end{tabular}

shows that most of the hypothesized mediating effects are supported. We can see several interesting findings regarding the mediating effects by examining the two combinations. First, Combination I yields the following conclusions regarding proposed mediating effects: (D1) PEOU does not mediate PE's impacts on BI because the assumed significant $\mathrm{PE} \rightarrow \mathrm{BI}$ link is not satisfied, (D2) PEOU partially mediates PE's impact on PU, and (D3) PE fully mediates CP's impact on PEOU.

Similarly, we can draw the following conclusions from Combination II: (D4) PE does not mediate PEOU's impact on $\mathrm{BI}$ because the PEOU $\rightarrow \mathrm{BI}$ link is not weakened after introducing PE, (D5) PE partially mediates PEOU's impact on PU, and (D6) PEOU partially mediates CP's impact on PE.

These two sets of conclusions cannot be true simultaneously because they include conflicting assumptions regarding the causal directions between PE and PEOU. The statistical results, however, cannot provide us with additional information for one view or the other. In other words, Table 6 shows that covariance-based methods such as the SEM are limited in detecting causal relationships. While they are powerful in examining causal connectedness, they are limited in examining causal direction. In fact, SEM is of a confirmatory nature, and researchers have to assume a causal relationship before collecting or analyzing data (Goldberger, 1972). 
TABLE 6. Structural models.

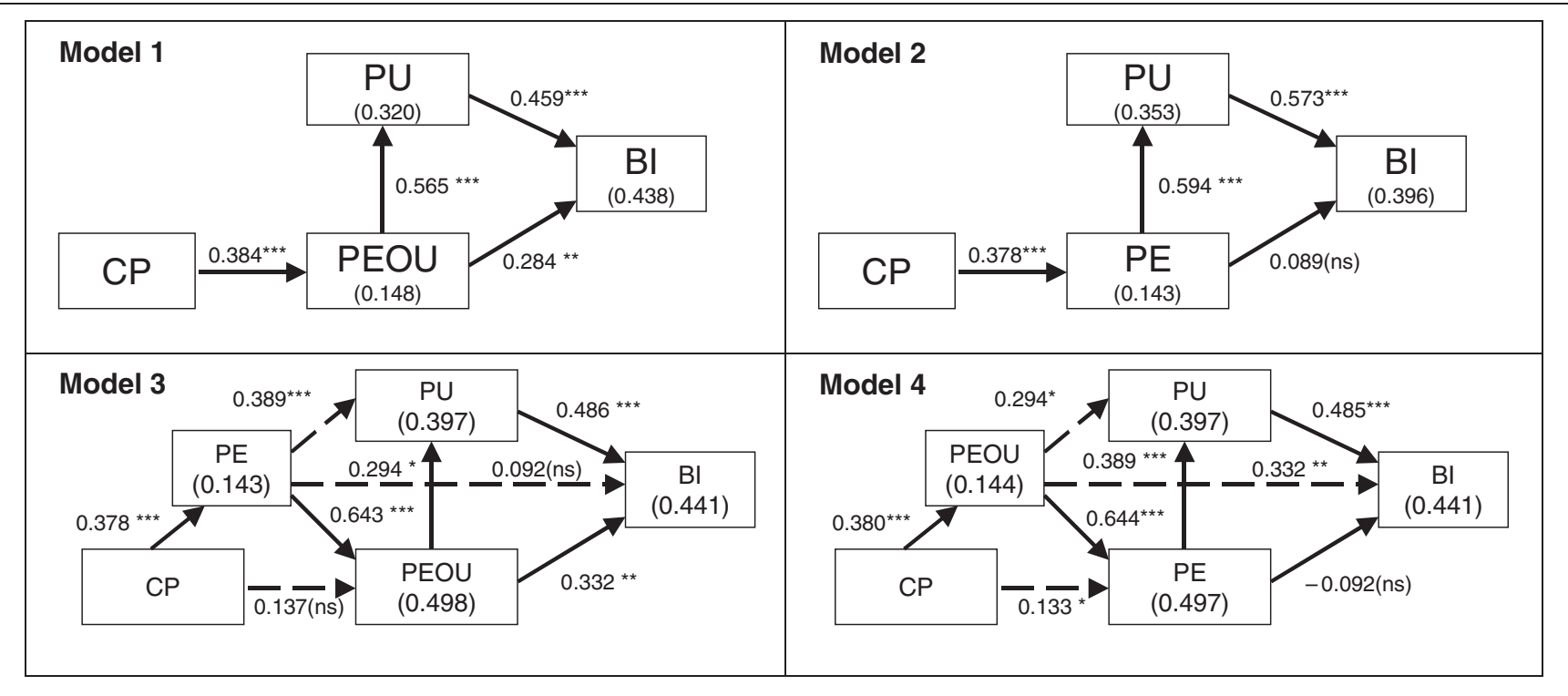

Dashed lines represent the hypothesized weakened relationships due to the mediating effects. ${ }^{*} p<.05 .{ }^{* *} p<.01 .{ }^{* * *} p<.001$. n.s. $=$ nonsignificant.

TABLE 7. Results of mediating effects in Combinations I and II.

\begin{tabular}{|c|c|c|c|c|c|}
\hline \multicolumn{6}{|c|}{ Combination I } \\
\hline D1. PEOU: $\mathrm{PE} \rightarrow \mathrm{BI}$ & $(\mathrm{No})$ & D2. PEOU: $\mathrm{PE} \rightarrow \mathrm{PU}$ & (Partially mediate) & D3: PE: $\mathrm{CP} \rightarrow$ PEOU & (Fully mediate) \\
\hline Conditions & Result & Conditions & Result & Conditions & Result \\
\hline $\begin{array}{l}\mathrm{PE} \rightarrow \mathrm{PEOU} \text { is } \\
\quad \text { significant (Model 3); }\end{array}$ & Yes & $\begin{array}{l}\mathrm{PE} \rightarrow \mathrm{PEOU} \text { is } \\
\quad \text { significant (Model } 3) ;\end{array}$ & Yes & $\begin{array}{l}\mathrm{CP} \rightarrow \mathrm{PE} \text { is } \\
\quad \text { significant (Model 2); }\end{array}$ & Yes \\
\hline $\begin{array}{l}\mathrm{PE} \rightarrow \mathrm{BI} \text { is significant } \\
\quad(\text { Model 2); }\end{array}$ & No & $\begin{array}{l}\mathrm{PE} \rightarrow \mathrm{PU} \text { is significant } \\
\quad(\text { Model } 2)\end{array}$ & Yes & $\begin{array}{l}\mathrm{CP} \rightarrow \mathrm{PEOU} \text { is significant } \\
\quad(\text { Model } 1) ;\end{array}$ & Yes \\
\hline $\begin{array}{l}\mathrm{PE} \rightarrow \mathrm{BI} \text { link is weakened } \\
\text { when PEOU is added } \\
\text { (Model 3). }\end{array}$ & Yes & $\begin{array}{l}\mathrm{PE} \rightarrow \mathrm{PU} \text { link is weakened } \\
\text { when PEOU is present } \\
(\text { Model 3). }\end{array}$ & Yes & $\begin{array}{l}\mathrm{CP} \rightarrow \mathrm{PEOU} \text { link is weakened } \\
\text { when PE is added (Model 3). }\end{array}$ & Yes \\
\hline \multicolumn{6}{|c|}{ Combination II } \\
\hline D4: PE: PEOU $\rightarrow$ BI & (No) & D5: PE: PEOU $\rightarrow$ PU & (Partially mediate) & D6: PEOU: $\mathrm{CP} \rightarrow \mathrm{PE}$ & (Partially mediate) \\
\hline Conditions & Result & Conditions & Result & Conditions & Result \\
\hline $\begin{array}{l}\mathrm{PEOU} \rightarrow \mathrm{PE} \text { is } \\
\text { significant (Model 4); }\end{array}$ & Yes & $\begin{array}{l}\text { PEOU } \rightarrow \text { PE is significant } \\
\quad(\text { Model } 4)\end{array}$ & Yes & $\begin{array}{l}\mathrm{CP} \rightarrow \mathrm{PEOU} \text { is significant } \\
\quad(\text { Model } 1) ;\end{array}$ & Yes \\
\hline $\begin{array}{l}\mathrm{PEOU} \rightarrow \mathrm{BI} \text { is } \\
\quad \text { significant (Model } 1) ;\end{array}$ & Yes & $\begin{array}{l}\text { PEOU } \rightarrow \text { PU is significant } \\
\quad(\text { Model } 1)\end{array}$ & Yes & $\begin{array}{l}\mathrm{CP} \rightarrow \mathrm{PE} \text { is significant } \\
\quad(\text { Model } 2)\end{array}$ & Yes \\
\hline $\begin{array}{l}\mathrm{PEOU} \rightarrow \mathrm{BI} \text { link is } \\
\text { weakened when PE is } \\
\text { added (Model } 4 \text { ). }\end{array}$ & No & $\begin{array}{l}\text { PEOU } \rightarrow \text { PU link is } \\
\text { weakened when PE } \\
\text { is added (Model 4). }\end{array}$ & Yes & $\begin{array}{l}\mathrm{CP} \rightarrow \mathrm{PE} \text { link is weakened } \\
\text { when PEOU is added (Model } 4) \text {. }\end{array}$ & Yes \\
\hline
\end{tabular}

Because PEOU and PE are intrinsically related, both directions, $\mathrm{PE} \rightarrow \mathrm{PEOU}$ and $\mathrm{PEOU} \rightarrow \mathrm{PE}$, have been proposed. The covariance-based methods can confirm both of them (see Table 6). Thus, we need an alternative method to further clarify the causal direction. So we turn to Cohen et al.'s (1993) path analysis method for this purpose.

\section{Cohen et al.'s Path Analysis}

Cohen et al.'s (1993) method is a generalization of multiple linear regressions. Its underlying rationale is that estimated correlations based on path analysis should be as close as possible to actual correlations. The estimated correlations are calculated based on both the connectedness and the causal direction. Therefore, changes in causal direction will change the "paths" through which factors are connected to one another, which in turn cause changes in estimated correlations and in errors between actual and estimated correlations. Total squared error (TSE) is the measure for the errors between the actual and estimated correlations, and can be used to indicate which one among several alternative causal models fits the dataset better (Cohen et al., 1993). TSE can be used as an indicator of how a proposed model is supported by data. A 
TABLE 8. Summary of path analysis.

\begin{tabular}{|c|c|c|c|c|c|c|c|}
\hline \multirow[b]{2}{*}{$\begin{array}{l}\text { Correlation } \\
\text { factors }\end{array}$} & \multicolumn{3}{|c|}{$\begin{array}{c}\text { Model 3: } \mathrm{PE} \rightarrow \mathrm{PEOU} \\
\text { Total squared error }(\mathrm{TSE} 1)=0.150\end{array}$} & \multicolumn{3}{|c|}{$\begin{array}{l}\text { Model 4: PEOU } \rightarrow \text { PE } \\
\quad \text { TSE2 }=0.242\end{array}$} & \multirow{2}{*}{$\begin{array}{c}\text { Model 3: Model } 4 \\
\text { Comparison of square } \\
\text { errors }^{b} \text { |SE1-SE2| }\end{array}$} \\
\hline & $\begin{array}{l}\text { Estimated } \\
\text { correlations } \\
\quad(\mathrm{EC} 1)\end{array}$ & $\begin{array}{c}\text { Actual } \\
\text { correlations } \\
\text { (AC1) }\end{array}$ & $\begin{array}{c}\text { Squared errors } \\
(\mathrm{SE} 1=\mathrm{AC} 1-\mathrm{EC} 1)^{\mathrm{b}}\end{array}$ & $\begin{array}{l}\text { Estimated } \\
\text { correlations } \\
\quad(\mathrm{EC} 2)\end{array}$ & $\begin{array}{c}\text { Actual } \\
\text { correlations } \\
(\mathrm{AC} 2)\end{array}$ & $\begin{array}{c}\text { Squared errors } \\
(\mathrm{SE} 2=\mathrm{AC} 2-\mathrm{EC} 2)\end{array}$ & \\
\hline BI: PU & 0.486 & 0.619 & 0.018 & 0.485 & 0.619 & 0.018 & 0 \\
\hline BI: PEOU & 0.475 & 0.542 & 0.005 & 0.537 & 0.542 & 0.000 & 0.005 \\
\hline BI: PE & 0.586 & 0.427 & 0.025 & 0.097 & 0.427 & 0.110 & 0.085 \\
\hline BI: CP & 0.287 & 0.131 & 0.024 & 0.217 & 0.131 & 0.007 & 0.017 \\
\hline PU: PEOU & 0.294 & 0.565 & 0.073 & 0.545 & 0.565 & 0.000 & 0.073 \\
\hline PU: PE & 0.578 & 0.594 & 0.000 & 0.389 & 0.594 & 0.042 & 0.042 \\
\hline PU: CP & 0.259 & 0.217 & 0.002 & 0.259 & 0.217 & 0.002 & 0 \\
\hline PEOU: PE & 0.643 & 0.694 & 0.003 & 0.644 & 0.694 & 0.003 & 0 \\
\hline PEOU: CP & 0.380 & 0.380 & 0.000 & 0.380 & 0.380 & 0.000 & 0 \\
\hline PE: CP & 0.378 & 0.378 & 0.000 & 0.133 & 0.378 & 0.060 & $\begin{array}{c}0.06 \\
\text { One-sample } t \text { test } \\
\begin{array}{c}(\mathrm{H} 0: \mu=0): \\
t=2.639 \\
p=.027 \\
n=10 \\
d f=9\end{array}\end{array}$ \\
\hline
\end{tabular}

${ }^{a} \mathrm{BI}$ : PU means we will identify all direct/indirect paths between these two factors and calculate the estimated correlation between them. We also have the actual correlation between them.

${ }^{\mathrm{b}}$ Absolute values of change are used because we care about the size of changes. That is, a change of -0.3 is larger than a positive change of 0.2 .

small TSE means the causal model is well supported by the data. Therefore, we can compare two models with different causal directions in terms of TSE and find the causal direction that results in a smaller TSE. Note that Sanguesa and Cortes (1997) argued that “[other than Cohen's algorithm], no other algorithm has been created for recovering path models [by 1997]" (p. 57). The usefulness of Cohen et al.'s method also has been acknowledged by several experiments and simulations (e.g., Anderson, Hart, Westbrook, \& Cohen, 1995; Cohen et al., 1993).

Cohen et al.'s (1993) path analysis follows a series of steps. First, it requires a prediction model and a corresponding path diagram. The prediction model can be described as $\bar{Y}=\rho_{Y X_{1}} X_{1}+\rho_{Y X 2} X_{2}+\rho_{Y X 3} X_{3}$ (a three-independentvariables model). The path coefficients are denoted by $\rho$. The second step is to tag each arc as a correlation or a beta coefficient $(\rho)$. In a multivariable situation $\left(X_{1}, X_{2}, X_{3}\right.$ as independent variables pointing to $Y$ as dependent variable), the rule is: (a) If $X_{1}, X_{2}, X_{3}$ are independent causes of $\bar{Y}$, then the path coefficients $\left(\rho_{Y X_{1}}, \rho_{Y X 2}, \rho_{Y X 3}\right)$ are the correlation coefficient; (b) if $X_{1}, X_{2}, X_{3}$ are dependent causes of $\bar{Y}$, then the path coefficients are standardized partial regression coefficients. Then, we can estimate the correlations between $X_{1}, X_{2}, X_{3}$ and $\bar{Y}$. This step involves finding the paths, direct or indirect, from each $X$ variable to $Y$, and summing the weights of the paths. To find the legal paths, Cohen et al. provided two rules: (a) A path cannot go through a node twice; (b) once a node has been entered by an arrowhead, no node can be left by an arrowhead; and (c) the model should not include more than one undirected arc (for independent causes).

Following Cohen et al.'s (1993) procedure, we calculated the TSE for Models 3 and 4. Table 8 indicates that
Model 3 has a much smaller TSE (0.150) than Model 4 (0.242). From Model 3 to Model 4, the error items change by $61 \%(=(0.242-0.150) / 0.150)$. The effect size is $0.30{ }^{1}$ The positive sign means the error items increase. From Model 4 to Model 3, the error items change by $-38 \%$ $(=(0.150-0.242) / 0.242)$. The effect size is -0.30 . The negative sign means that error items have actually decreased. Therefore, the data work in favor of Model 3.

To further test the significance of the difference between Models 3 and 4 in squared errors, a one-sample $t$ test was conducted. Our results show that the changes in squared errors between Models 3 and 4 are significant at the .05 level $(t=2.639, p=.027)$. Moreover, Model 3 has a smaller TSE. Therefore, we can say that Model 3 is significantly better than Model 4.

\section{Conclusions}

User technology acceptance continues to be one of the important issues for organizations and businesses to consider and for researchers to investigate. Despite the interest and efforts, the literature shows a lack of attention to in-depth examinations of affect factors and their roles in user technology acceptance. This can lead to some misleading results for both theoretical understanding and practice guidance. Acknowledging and resolving such limitations are important.

\footnotetext{
${ }^{1}$ There are many methods to calculate effect size. Here we use Cohen's $d$, which defines the effect size

$$
f^{2}=\frac{M_{2}-M_{1}}{\sqrt{\frac{\sigma_{1}^{2}+\sigma_{2}^{2}}{2}}}
$$
}


Aiming at a better understanding of the roles of affect in user technology acceptance, we identified two gaps regarding affect variables: (a) the unstudied relationships between two affect variables, CP and PE; and (b) the unclear causal relationship between PE and PEOU. We employed innovative methods to address these two gaps. As a result, this research gains a deeper understanding of not only "what" but also "how" and "why" affect factors influence user technology acceptance.

Following Baron and Kenny's (1986) rules and considering the previously proposed controversial causal directions between PE and PEOU, we composed four models consisting of 15 hypotheses. A systematic comparison of empirical results for Models 1 through 4 discloses the expected mediating effects. This research indicates that PEOU partially mediates PE's relationships on PU, and PE fully mediates CP's impacts on PEOU. That is, PE is a single, robust mediator of the impact of CP on PEOU. This finding is different from previous empirical studies in which $\mathrm{CP}$ and PE tended to be considered as two independent antecedents of PEOU (e.g., Venkatesh, 2000).

This research confirms the robustness of PE in influencing PU and PEOU. PE has a direct impact on PU in addition to an indirect impact via PEOU. When PE is included, the $R^{2}$ of PEOU increased dramatically, from .148 to .498.

Findings from this research suggest that $\mathrm{CP}$ alone explains a significant part of the variance in PE (14.3\%). A consideration of $\mathrm{CP}$ has been recommended as one way to measure the hedonic disposition of IT users (Van der Heijden, 2004). Broadly speaking, this research confirms the importance of individual dispositional factors apart from technological features such as the technology's affective quality (e.g., Kim, Lee, \& Choi, 2003; Zhang \& Li, 2004).

Besides theoretical contributions, this research also has methodological implications. It demonstrates that Cohen et al.'s (1993) path analysis method can supplement widely used covariance-based statistical methods. Cohen et al.'s method is especially useful in conditions where conceptually closely related factors (e.g., PE and PEOU) are present simultaneously.

Our empirical findings show relatively high intercorrelations among PE, PEOU, and PU, although items in our study demonstrated satisfactory convergent and discriminant validity through item loadings and comparisons between average variance extracted and correlation items. In fact, high correlations are not uncommon in TAM-related studies (e.g., Wixom \& Todd, 2005). Despite the fact that they are correlated conceptually, it is possible that the research method and context may account for some of these high correlations. In this research, general search engines instead of a specific search engine were used as the target technology. The high correlations among PE, PEOU, and PU could be an artifact of the differences among search engines. Future studies may need to be more specific on which search engine is of interest.

We caution readers that we by no means deny the existence of the PEOU $\rightarrow \mathrm{PE}$ direction. Both directions exist, and one may dominate over the other one under some conditions, which is referred as "conditional dominance of causal direction" (Sun \& Zhang, 2006b). That is, we should be aware of the conditions under which the causal direction is studied. It is possible that under certain circumstances, the PEOU $\rightarrow$ $\mathrm{PE}$ direction could be better held by data than the $\mathrm{PE} \rightarrow \mathrm{PEOU}$ direction. This is actually an interesting topic by itself for future research.

This research has practical implications. First, we highlight the significant mediating effects of PE and the significant $R^{2}$ of PEOU explained by PE. It has been argued that a consideration of personal traits should be an important ingredient in training programs (Potosky, 2002; Webster \& Martocchio, 1992). Our research suggests that we should give priority to the enhancement of system-specific PE (e.g., through game-based training) (Venkatesh et al., 2002). Second, the causal direction of $\mathrm{PE} \rightarrow \mathrm{PEOU}$ suggests that the perception of enjoyment of technology can be a strong candidate for consideration when there are no means to change PEOU directly. Practitioners can focus on designing and testing managerial interventions to enhance PEOU by targeting PE, with an eye towards fostering increased user technology acceptance in the workplace. This is especially true for complex systems, which often encounter resistance because of their complexity. In this case, enhanced enjoyment can be used as an alternative to buffer the possible negative effects of the complexity of the system.

\section{References}

Agarwal, R., \& Karahanna, E. (2000). Time flies when you're having fun: Cognitive absorption and beliefs about information technology usage. MIS Quarterly, 24(4), 665-694.

Anderson, S.D., Hart, D.M., Westbrook, D.L., \& Cohen, P.R. (1995). A toolbox for analyzing programs. Journal of Artificial Intelligence Tools, 4(1), 257-279.

Atkinson, M.A., \& Kydd, C. (1997). Individual characteristics associated with World Wide Web use: An empirical study of playfulness and motivation. DATA BASE for Advances in Information Systems, 28(2), 53-62.

Bagozzi, R.P., Gopinath, M., \& Nyer, P.U. (1999). The role of emotions in marketing. Journal of the Academy of Marketing Science, 27(2), 184-206.

Bandura, A. (1977). Self-efficacy: Towards a unifying theory of behavioral change. Psychological Review, 84, 191-215.

Bandura, A. (1986). Social foundations of thought and action. Englewood Cliffs, NJ: Prentice Hall.

Barclay, D., Higgins, C.A., \& Thompson, R.L. (1995). The partial least squares (PLS) approach to causal modeling: Personal computer adoption and use as an illustration. Technology Studies, 2(2), 285-309.

Baron, R.M., \& Kenny, D. (1986). The moderator-mediator variable distinction in social psychological research: Conceptual, strategic, and statistical considerations. Journal of Personality and Social Psychology, 51(6), 1173-1182.

Batra, R., \& Ray, M.L. (1986). Affective responses mediating acceptance of advertising. Journal of Consumer Research, 13, 234-249.

Chu, H., \& Rosenthal, M. (1996). Search engines for the World Wide Web: A comparative study and evaluation methodology. Paper presented at the annual Conference of the ASIS, October, Baltimore, MD.

Cohen, P.R., Carlsson, A., Ballesteros, L., \& Amant, R.S. (1993). Automating path analysis for building causal models from data. Paper presented the International Conference on Machine Learning, June 1993, Amherst, NY.

Compeau, D.R., Higgins, C.A., \& Huff, S. (1999). Social cognitive theory and individual reactions to computing technology: A longitudinal study. MIS Quarterly, 23(2), 145-158. 
Csikszentmihalyi, M. (1988). The flow experience and human psychology. In M. Csikszentmihalyi \& I.S. Csikszentmihalyi (Eds.), Optimal experience: Psychological studies of flow in consciousness (pp. 15-35). New York: Cambridge University Press.

Csikszentmihalyi, M. (1990). Flow: The psychology of optimal experience. New York: Harpers Perennial.

Csikszentmihalyi, M. (2000). Happiness, flow and economic equality. American Psychologist, 55(10), 1163-1164.

Davis, F.D. (1989). Perceived usefulness, perceived ease of use, and user acceptance of information technology. MIS Quarterly, 13(3), 319-342.

Davis, F.D., Bagozzi, R.P., \& Warshaw, P.R. (1989). User acceptance of computer technology: A comparison of two theoretical models. Management Science, 35(8), 982-1003.

Davis, F.D., Bagozzi, R.P., \& Warshaw, P.R. (1992). Extrinsic and intrinsic motivation to use computers in the workplace. Journal of Applied Social Psychology, 22, 1111-1132.

Davis, F.D., \& Venkatesh, V. (1996). A critical assessment of potential measurement biases in the technology acceptance model: Three experiments. Journal of Human-Computer Studies, 45(1), 19-45.

Day, D.V., \& Silverman, S.B. (1989). Personality and job performance: Evidence of incremental validity. Personnel Psychology, 42(1), 25-36.

Forgas, J.P. (1995). Mood and judgment: The affect infusion model (AIM). Psychological Bulletin, 117, 39-66.

Fornell, C., \& Larcker, D. (1981). Evaluating structural equation models with unobservable variables and measurement error. Journal of Marketing Research, 18, 39-50.

Gefen, D., Karahanna, E., \& Straub, D.W. (2003). Trust and TAM in online shopping: An integrated model. MIS Quarterly, 27(1), 51-90.

Goldberger, A.S. (1972). Structural equation models in the social sciences. Econometrica, 40, 979-1001.

Hackbarth, G., Grover, V., \& Yi, M.Y. (2003). Computer playfulness and anxiety: Positive and negative mediators of the system experience effect on perceived ease of use. Information \& Management, 40(3), 221.

Hsu, C.L., \& Lu, H.P. (2004). Why do people play on-line games? An extended TAM with social influences and flow experience. Information \& Management, 41(7), 853-868.

Hu, P.J., Chau, P.Y.K., Sheng, O.R.L., \& Tam, K.Y. (1999, Fall). Examining the Technology Acceptance Model using physician acceptance of telemedicine technology. Journal of Management Information Systems, $16,91-112$.

Igbaria, M., Iivari, J., \& Maragahh, H. (1995). Why do individuals use computer technology? A Finnish case study. Information \& Management, 29(5), 227-238.

Igbaria, M., Parasuraman, S., \& Baroudi, J.J. (1996). A motivational model of microcomputer usage. Journal of Management Information Systems, 13(1), 127.

Kim, J., Lee, J., \& Choi, D. (2003). Designing emotionally evocative homepages: An empirical study of the quantitative relations between design factors and emotional dimensions. Journal of Human-Computer Studies, 59(6), 899-940.

Legris, P., Ingham, J., \& Collerette, P. (2003). Why do people use information technology? A critical review of the technology acceptance model. Information \& Management, 40(3), 191-204.

Liljander, V., \& Mattsson, J. (2002). Impact of customer preconsumption mood on the evaluation of employee behavior in service encounters. Psychology \& Marketing, 19(10), 837-860.

Liu, C., \& Arnett, K.P. (2000). Exploring the factors associated with Web site success in the context of electronic commerce. Information \& Management, 38(1), 23-33.

Mathieson, K. (1991). Predicting user intentions: Comparing the Technology Acceptance Model with the theory of planned behavior. Information Systems Research, 2(3), 173-191.

Moon, J.W., \& Kim, Y.G. (2001). Extending the TAM for a World-Wide-Web context. Information \& Management, 38(4), 217-230.

Novak, T.P., Hoffman, D.L., \& Duhachek, A. (2002). The influence of goaldirected and experiential activities on online flow experiences. Journal of Consumer Psychology, 13(1/2), 3-16.
Potosky, D. (2002). A field study of computer efficacy beliefs as an outcome of training: The role of computer playfulness, computer knowledge, and performance during training. Computers in Human Behavior, 18(3), 241-255.

Ryan, R.M., \& Deci, E.L. (2000). Intrinsic and extrinsic motivations: Classic definitions and new directions. Contemporary Educational Psychology, 25, 54-67.

Sanguesa, R., \& Cortes, U. (1997). Learning causal networks from data: A survey and a new algorithm for recovering possibilistic causal networks. AI Communications, 10, 31-61.

Sun, H., \& Zhang, P. (2006a). The role of moderating factors in user technology acceptance. Journal of Human-Computer Studies, 64(2), 53-78.

Sun, H., \& Zhang, P. (2006b). Causal relationships between perceived enjoyment and perceived ease of use: An alternative approach. Journal of the Association for Information Systems, 7(9), 618-645.

Taylor, S., \& Todd, P.A. (1995a). Assessing IT usage: The role of prior experience. MIS Quarterly, 19(4), 561-570.

Teo, T.S.H., Lim, V.K.G., \& Lai, R.Y.C. (1999). Intrinsic and extrinsic motivation in Internet usage. Omega, 27(1), 25-37.

Thatcher, J.B., \& Perrewe, P.L. (2002). An empirical examination of individual traits as antecedents to computer anxiety and computer self-efficacy. MIS Quarterly, 26(4), 381-396.

Van der Heijden, H. (2004). User acceptance of hedonic information systems. MIS Quarterly, 28(4), 695-704.

Venkatesh, V. (1999). Creation of favorable user perceptions: Exploring the role of intrinsic motivation. MIS Quarterly, 23(2), 239.

Venkatesh, V. (2000). Determinants of perceived ease of use: Integrating control, intrinsic motivation, and emotion into the technology acceptance model. Information Systems Research, 11(4), 342-365.

Venkatesh, V., \& Davis, F. (1996). A model of the antecedents of perceived ease of use: Development and test. Decision Science, 27(3), 451-481.

Venkatesh, V., Morris, M.G., Davis, G.B., \& Davis, F.D. (2003). User acceptance of information technology: Toward a unified view. MIS Quarterly, 27(3), 425-478.

Venkatesh, V., Speier, C., \& Morris, M.G. (2002). User acceptance enablers in individual decision making about technology: Toward an integrated model. Decision Sciences, 33(2), 297.

Webster, J., \& Martocchio, J.J. (1992). Microcomputer playfulness: Development of a measure with workplace implications. MIS Quarterly, 16(2), 201-226.

Webster, J., \& Martocchio, J.J. (1995). The differential effects of software training previews on training outcomes. Journal of Management, 21(4), 757-787.

Webster, J., Trevino, L.K., \& Ryan, L. (1993). The dimensionality and correlates of flow in human-computer interactions. Computers in Human Behavior, 9(4), 411-426.

Weiss, H.M. (2002). Deconstructing job satisfaction separating evaluations, beliefs, and affective experiences. Human Resource Management Review, 12, 173-194.

Weiss, H.M., Nicholas, J.P., \& Daus, C.S. (1999). An examination of the joint effects of affective experiences and job beliefs on job satisfaction and variations in affective experiences over time. Organizational Behavior and Human Decision Processes, 78(1), 1-24.

Wixom, B.H., \& Todd, P.A. (2005). A theoretical integration of user satisfaction and technology acceptance. Information Systems Research, 16(1), 85-102.

Yager, S.E., Kappelman, L.A., Maples, G.A., \& Prybutok, V.R. (1997). Microcomputer playfulness: Stable or dynamic trait? DATA BASE for Advances in Information Systems, 28(2), 43-52.

Yi, M.Y., \& Hwang, Y. (2003). Predicting the use of web-based information systems: Self-efficacy, enjoyment, learning goal orientation, and the technology acceptance model. Journal of Human-Computer Studies, 59(4), 431-449.

Zajonc, R.B. (1980). Feeling and thinking: Preferences need no inferences. American Psychologist, 35, 151-175.

Zajonc, R.B., \& Markus, H. (1982). Affective and cognitive factors in preferences. Journal of Consumer Research, 9(2), 123-131. 
Zhang, P., \& Li, N. (2004). Love at first sight or sustained effect? The role of perceived affective quality on users' cognitive reactions to IT. Paper presented at the International Conference on Information Systems (ICIS '04), December, Washington, DC.

\section{Appendix}

A 7-point Likert scale was used for all items.

Computer Playfulness

CPS1: When using the Web I am Spontaneous.

CPS2: When using the Web I am Imaginative.

CPS3: When using the Web I am Flexible.

CPS4: When using the Web I am Creative.

CPS5: When using the Web I am Playful.

CPS6: When using the Web I am Original.

CPS7: When using the Web I am Inventive.

Perceived Enjoyment

PE1: I find using search engines to be enjoyable.

PE2: The actual process of using search engines is pleasant.

PE3: I have fun using search engines.
Perceived Ease of Use

PEOU1: Learning to operate search engines is easy for me.

PEOU2: I find it easy to get the search engines to do what I want it to do.

PEOU3: It is easy for me to become skillful at using search engines.

PEOU4: I find search engines easy to use.

Perceived Usefulness

PU1: Using search engines enhances my effectiveness in work.

PU2: Using search engines enhances my productivity.

PU3: I find search engines useful in my work.

PU4: Using search engines improves my performance in work.

Behavioral Intention

BI1: I intend to use search engines in the future.

BI2: I predict I would use search engines in the in the future. 